\title{
A hairy-leaf gene, BLANKET LEAF, of wild Oryza nivara increases photosynthetic water use efficiency in rice
}

\author{
Norimitsu Hamaoka', Hideshi Yasui', Yoshiyuki Yamagata', Yoko Inoue ${ }^{1}$, Naruto Furuya', Takuya Araki², \\ Osamu Ueno ${ }^{1}$ and Atsushi Yoshimura ${ }^{1 *}$
}

\begin{abstract}
Background: High water use efficiency is essential to water-saving cropping. Morphological traits that affect photosynthetic water use efficiency are not well known. We examined whether leaf hairiness improves photosynthetic water use efficiency in rice.

Results: A chromosome segment introgression line (IL-hairy) of wild Oryza nivara (Acc. IRGC105715) with the genetic background of Oryza sativa cultivar 'IR24' had high leaf pubescence (hair). The leaf hairs developed along small vascular bundles. Linkage analysis in $\mathrm{BC}_{5} \mathrm{~F}_{2}$ and $\mathrm{F}_{3}$ populations showed that the trait was governed by a single gene, designated BLANKET LEAF (BKL), on chromosome 6. IL-hairy plants had a warmer leaf surface in sunlight, probably due to increased boundary layer resistance. They had a lower transpiration rate under moderate and high light intensities, resulting in higher photosynthetic water use efficiency.
\end{abstract}

Conclusion: Introgression of BKL on chromosome 6 from O. nivara improved photosynthetic water use efficiency in the genetic background of IR24.

Keywords: Leaf hair, Oryza nivara, Photosynthetic trait, Water use efficiency, Wild rice

\section{Background}

Rice is a major staple food around the world. Nearly half of the rice-growing area is rainfed uplands or lowlands (Kato et al. 2008), but the productivity of those fields is generally lower than that of irrigated lowlands. Irrigated lowlands produce $75 \%$ of all rice grain, and water-limited areas produce 23\% (Maclean et al. 2013). Therefore, effective use of water resources is an important target for sustainable rice cropping.

In adapting to new environments, plants gain or lose ecological, morphological, physiological, and anatomical traits (Lande 2009; Nicotra et al. 2010). Many higher plant species have leaf hairs, called glandular or nonglandular trichomes (Zeng et al. 2013). These leaf hairs have important roles such as protection from herbivory by insects and infection by pathogens, reflecting excess

\footnotetext{
*Correspondence: ayoshi@agr.kyushu-u.ac.jp

${ }^{1}$ Faculty of Agriculture, Kyushu University, 6-10-1 Hakozaki, Higashi-ku,

Fukuoka 812-8581, Japan

Full list of author information is available at the end of the article
}

radiation, and reducing water loss (Levin 1973; Symonds et al. 2005). Their functional role varies with plant species and growth environment. However, the function of leaf hairs in rice remains unknown.

Various genes related to leaf morphological traits in rice, including narrow leaf (nal), rolled leaf $(r l)$, drooping leaf $(d l)$, dripping-wet leaf $(d r p)$, and glabrous leaf $(g l)$, have been identified, and their modes of inheritance have been elucidated in mutant lines (Kinoshita 1995). DNA markers have facilitated the genetic mapping of quantitative trait loci (QTLs) and the map-based cloning of genes for morphological and physiological leaf traits (Yonemaru et al. 2010). The rice hairy-leaf genes, Hla and Hlb (Nagao et al. 1960; Nagao and Takahashi 1963), also affect the hairiness of husks. Recently, a dominant gene for pubescence growth and development, GL6, was fine-mapped on chromosome 6 (Zeng et al. 2013).

In general, plant water use efficiency (WUE) is calculated as the amount of dry matter produced divided by the amount of water consumed by the plant during its 
growth (Condon et al. 2004), and photosynthetic WUE $\left(W_{\mathrm{u}}\right)$ is defined as the amount of carbon fixed in photosynthesis per unit of water transpired (Hamid et al. 1990; Lawson and Blatt 2014). Plant WUE and WUE have a close relationship in some crop species (Heitholt 1989; Peng and Krieg 1992). Leaf morphological traits commonly affect physiological traits such as $\mathrm{CO}_{2}$ gas exchange and transpiration (Wright et al. 2004). Leaf hairs might influence photosynthesis (Johnson 1975; Pfeiffer et al. 2003). Although the physiological effects of leaf hairs in rice have been reported (Wada 2002), it is not well known how leaf hairs relate to photosynthetic traits or water use at the leaf level.

Here, we developed a chromosomal segment introgression line (IL) of the wild rice species Oryza nivara in the genetic background of Oryza sativa 'IR24' with a high leaf-hair density. Using genetic, physiological, and morphological analysis, we examined the effects of the leaf hairs on photosynthesis and WUE at the leaf level.

\section{Results}

A gene on chromosome 6 controls hairy-leaf trait of 0 .

nivara

Oryza nivara accession IRGC105715 had a high leafhair density (hairy leaf), whereas IR24 had few hairs (Fig. 1a, b). In the $\mathrm{BC}_{4} \mathrm{~F}_{4}$ generation derived from a cross between IR24 and IRGC105715, one of the ILs showed the hairy-leaf trait from the sixth leaf to the flag leaf, and was named IL-hairy (Fig. 1c, d). To identify the chromosomal segments derived from IRGC105715, we determined the genotypes of the $\mathrm{BC}_{4} \mathrm{~F}_{3}$ parent of ILhairy using simple sequence repeat (SSR) markers covering the whole rice genome (Additional file 1: Table S1). IL-hairy had two segments derived from IRGC105715: at SSR marker RM7302 on the short arm of chromosome 5 and from RM8226 to RM3138 on chromosome 6, all homozygous for the IRGC105715 regions (Fig. 1e). To identify the gene controlling leaf hairiness in IL-hairy, we conducted linkage analysis using $189 \mathrm{BC}_{5} \mathrm{~F}_{2}$ plants derived from backcrossing between IL-hairy and IR24.
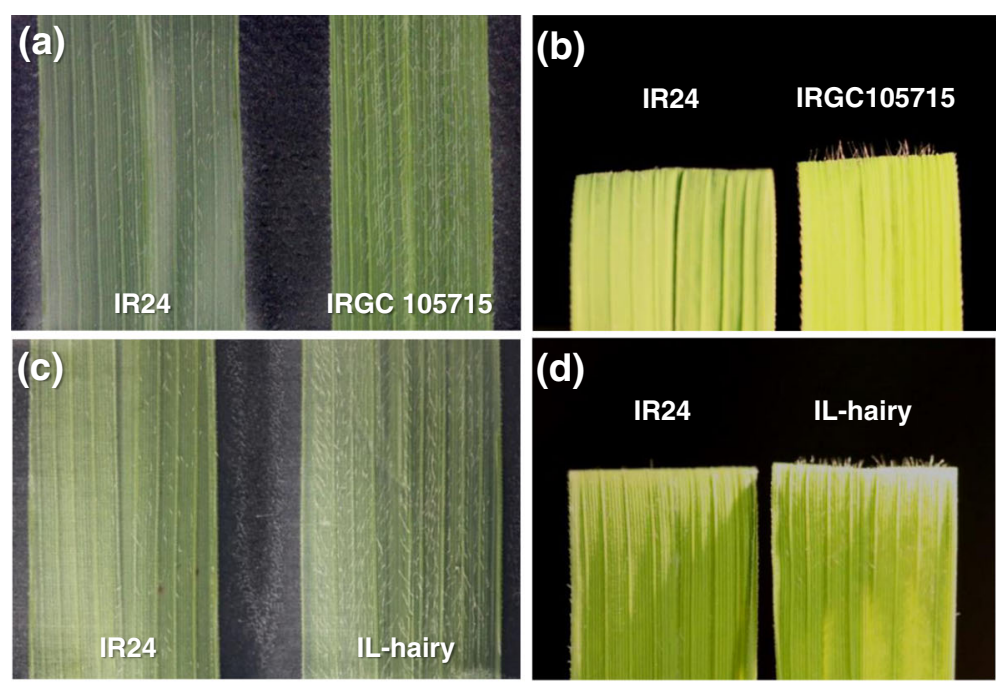

(e)

(f)
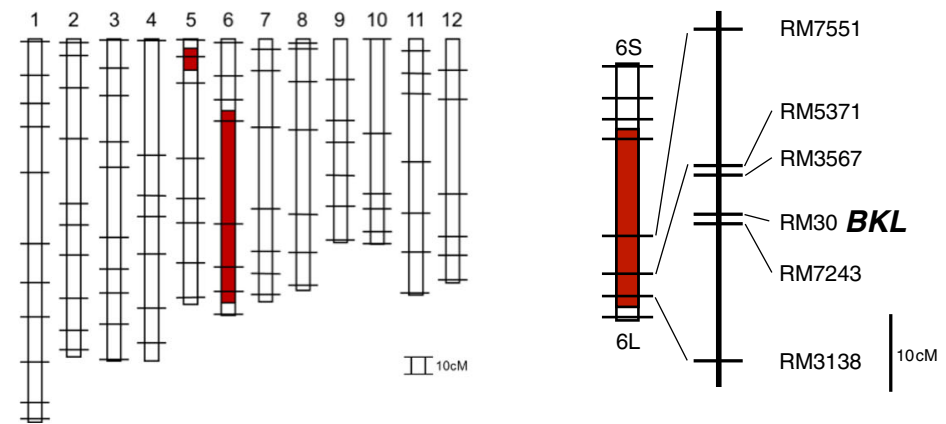

Fig. 1 Phenotypes of leaf surface, graphical genotype of IL-hairy, and linkage map of BKL on chromosome 6. a-d Phenotypes of leaf hairs in vertical $(\mathbf{a}, \mathbf{c})$ and horizontal (b, d) view of IR24 and IRGC105715 (a, b) and IR24 and IL-hairy (c, d). e Graphical genotype of IL-hairy used for linkage analysis in $\mathrm{BC}_{5} \mathrm{~F}_{2}$. Chromosomal segments derived from IRGC105715 and IR24 are indicated in red and white, respectively. $\mathbf{f}$ Vertical bars represent the positions of SSR markers. Numbers indicate map distances (cM) between SSR markers 
In this population, plants with hairy leaves and plants with normal (sparsely haired) leaves segregated in a 137:52 ratio. The $189 \mathrm{BC}_{5} \mathrm{~F}_{3}$ families derived from the $\mathrm{BC}_{5} \mathrm{~F}_{2}$ individuals were classified into three groups: 36 populations in which all $\mathrm{BC}_{5} \mathrm{~F}_{3}$ plants had the hairy-leaf phenotype, 101 populations in which hairy-leaf and normal-leaf plants segregated, and 52 populations in which all $\mathrm{BC}_{5} \mathrm{~F}_{3}$ plants had the normal-leaf phenotype (Additional file 2: Table S2). The segregation fitted a $1: 2: 1$ ratio, indicating that hairy leaf was controlled by a single dominant gene $\left(\chi_{1: 2: 1}^{2}=3.60, P=0.17\right)$. We designated this gene BLANKET LEAF $(B K L)$. Our linkage analysis using SSR makers on chromosome 6 revealed that $B K L$ tightly linked to RM30 (Fig. 1f). These data indicate that a single dominant gene tightly linked to RM30 controls leaf hairiness in the $\mathrm{BC}_{5} \mathrm{~F}_{2}$ and $\mathrm{BC}_{5} \mathrm{~F}_{3}$ populations. $B K L$ also located between SSR markers RM3567 and RM7243 at map distances of 5.8 and $1.1 \mathrm{cM}$, respectively (Fig. 1f).

\section{Morphological characteristics of leaf hair}

In leaf blades of rice, macro-hairs array on silica cells over small vascular bundles, and micro-hairs and glandular hairs occur along stomatal rows or beside motor cells ( $\mathrm{Li}$ et al. 2010, Fig. 2a-d). Leaves of IR24 had few elongated macrohairs and many short macro-hairs along the small vascular bundles (Fig. 2a). In contrast, IL-hairy leaves had few short macro-hairs and many elongated macro-hairs along the small vascular bundles (Fig. 2b). The two types of macrohair, short and elongated types, occurred over small vascular bundle (Fig. 2b-d).

At the booting stage, the densities of elongated macrohairs on each leaf surface were much greater in IL-hairy than in IR24; the total density on both leaf surfaces in ILhairy was 7.9 times that in IR24 (Fig. 2e). The lengths of elongated macro-hairs ranged between 300 and $400 \mu \mathrm{m}$ in IR24 and between 500 and $800 \mu \mathrm{m}$ in IL-hairy. In IR24 and IL-hairy, there was no difference in length between adaxial and abaxial surfaces (data not shown). Furthermore, at the tillering stage, total macro-hair (sum of elongated and short types of macro-hair) densities on both leaf surfaces did not different between two lines, although elongated macro-hair densities on both surfaces were also much greater in IL-hairy than in IR24 (Table 1). On the basis of the localization of macro-hairs and total macrohair density, we considered that the elongated macrohairs in IL-hairy are originated from short macro-hairs. In addition, hull hairiness showed no difference between IR24 and IL-hairy (Additional file 3: Fig. S1).

\section{Comparison of physiological and morphological traits between IL-hairy and IR24}

Because the dense leaf hairs of IL-hairy would act as a blanket and thus affect leaf physiology, we measured daytime leaf surface temperatures. The leaf surface of IL-hairy was 1 to $2{ }^{\circ} \mathrm{C}$ warmer than that of IR24 at both plant (Fig. 3a, b) and canopy levels (Fig. 3c, d). We measured photosynthetic traits under a moderate light intensity (ML) of $400 \mu \mathrm{mol}$ photons $\mathrm{m}^{-2} \mathrm{~s}^{-1}$ and a high light intensity (HL) of $1500 \mu \mathrm{mol}$ photons $\mathrm{m}^{-2} \mathrm{~s}^{-1}$. Under $\mathrm{HL}$, the net photosynthetic rate $\left(P_{\mathrm{n}}\right)$, transpiration rate $\left(T_{\mathrm{r}}\right)$, and leaf diffusive conductance $\left(g_{\mathrm{l}}\right)$ of IL-hairy were significantly lower and $\mathrm{WUE}_{\mathrm{p}}$ was significantly higher (by 13\%) than those of IR24 (Fig. 4a-d). Under ML also, $P_{\mathrm{n}}$ was marginally lower, $T_{\mathrm{r}}$ and $g_{\mathrm{l}}$ of IL-hairy were significantly lower, and $\mathrm{WUE}_{\mathrm{p}}$ was significantly higher (by $44 \%$ ) than those of IR24. These data suggest that ILhairy has lower photosynthetic activity but higher $\mathrm{WUE}_{\mathrm{p}}$ than IR24.

We evaluated morphological and physiological leaf traits related to photosynthesis. In both lines, stomatal density was approximately 35\% higher on the abaxial surface than on the adaxial surface, but there was no difference in stomatal density or guard cell length on either surface between the lines (Table 2). Specific leaf weight (SLW), as an indicator of leaf thickness, was not significantly different between lines. Values of chlorophyll, which is involved in photosynthetic rate by regulating energy production, and of leaf nitrogen, as a component of ribulose 1,5-bisphosphate carboxylase/oxygenase, were similar between lines (Table 2).

Shoot dry weight and leaf area per hill did not differ significantly between lines at the vegetative stage in the field and at the heading stage in pots (Fig. 5a). In addition, other growth traits such as plant height, tiller number, leaf age, leaf SPAD value, and length and width of grain also did not significantly differ between lines (Additional file 4: Table S3, Additional file 3: Fig. S1). We also compared water diminution per a potted plant through transpiration during 5 days at the booting stage. As expected, IL-hairy showed significantly lower water diminution than IR24 from two to 5 days after stop of watering (Fig. 5b), and also ratio of water weight in the pot for IL-hairy to that of IR24 increased with the passage of time after stop of watering (Fig. 5b).

\section{Discussion}

\section{Genetic analysis of hairy leaf gene $B K L$}

Many studies of genotypic differences in plant growth and water use under drought, upland, and water-saving conditions have been carried out in rice. A large number of QTLs related to root traits under water-limited conditions have been identified (Zhang et al. 2001; Bernier et al. 2008; Kamoshita et al. 2008; Ding et al. 2011). QTLs for leaf water use and photosynthesis have been identified in rice by using carbon isotope discrimination values as an index (Price et al. 2002; Takai et al. 2009; Xu et al. 2009; This et al. 2010). However, there is little 


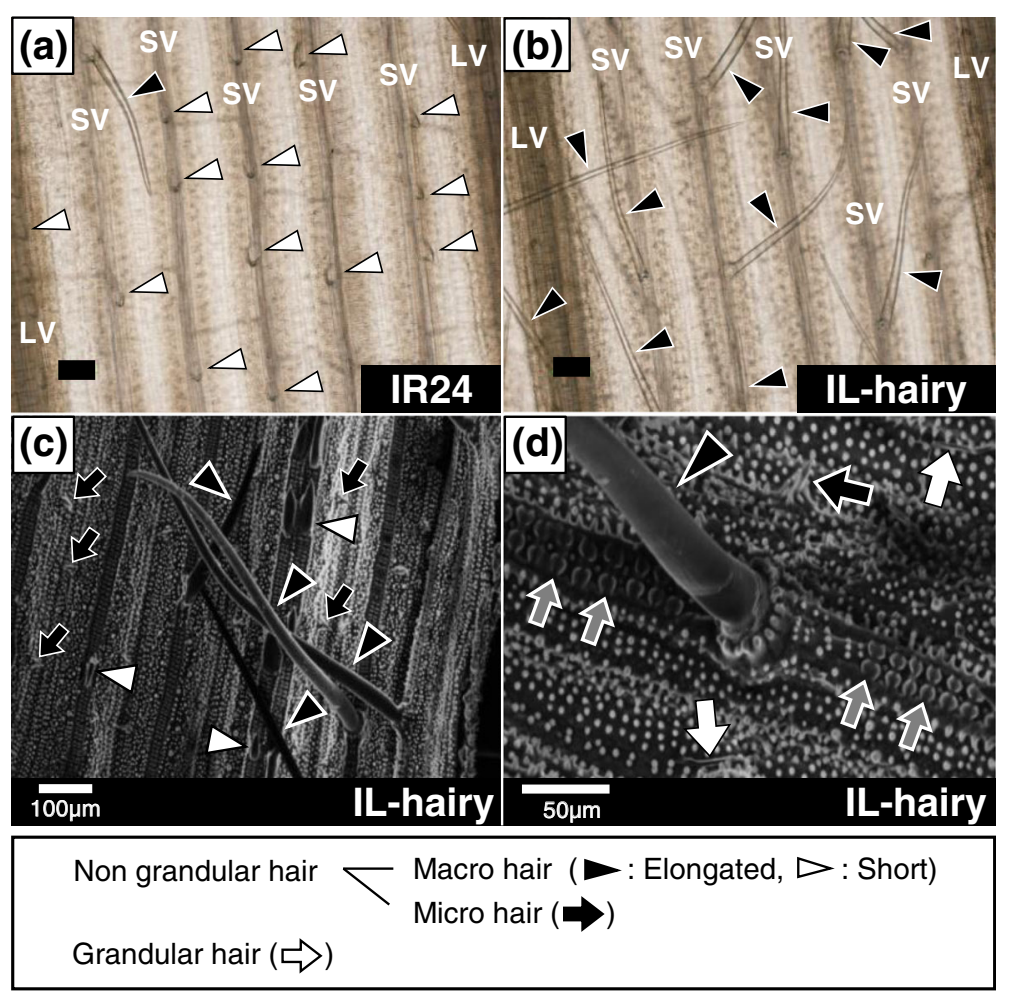

(e)

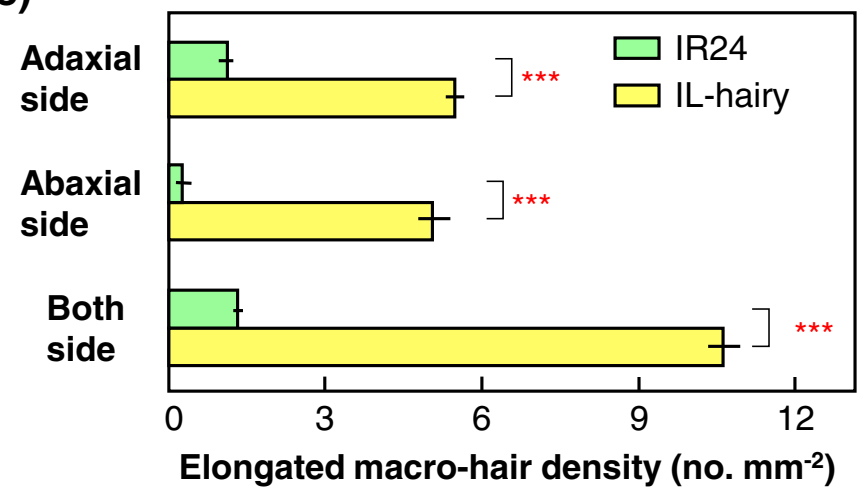

Fig. 2 Light microscopic and scanning electronic microscopic images of leaf surface, and leaf hair density. $\mathbf{a}$, b Light microscopic images of IR24 (a) and IL-hairy (b). Scale bars, 100 um. c, d Scanning electronic microscopic images of adaxial surface of IL-hairy at tillering stage. Black arrowheads, elongated macro-hairs; white arrowheads, short macro-hairs; black arrows, micro-hairs; white arrows, glandular hairs; gray arrows, silica cells. LV, large vascular bundle; SV, small vascular bundle. e Density of elongated macro-hairs on adaxial side, abaxial side, and both sides in leaves of IR24 and IL-hairy at booting stage. Data are means \pm SD $(n=3$ or 4$) .{ }^{* *} P=0.001$ by Student's $t$-test

Table 1 Elongated macro-hair density and total macro-hair (sum of elongated and short types of macro-hair) density of leaves in IR24 and IL-hairy at the tillering stage

\begin{tabular}{|c|c|c|c|c|}
\hline \multirow[t]{2}{*}{ Line } & \multicolumn{2}{|c|}{ Elongated macro-hair density $\left(\mathrm{no} \mathrm{mm}^{-2}\right.$ ) } & \multicolumn{2}{|c|}{ Total macro-hair density $\left(\mathrm{no} \mathrm{mm}^{-2}\right)$} \\
\hline & Adaxial & Abaxial & Adaxial & Abaxial \\
\hline IR24 & $0.1 \pm 0.3$ & $0.0 \pm 0.0$ & $15.2 \pm 2.0$ & $6.9 \pm 2.3$ \\
\hline \multirow[t]{2}{*}{ IL-hairy } & $3.5 \pm 0.5$ & $3.8 \pm 0.4$ & $16.4 \pm 1.5$ & $7.0 \pm 1.5$ \\
\hline & $* * *$ a & $* * *$ & ns & ns \\
\hline
\end{tabular}



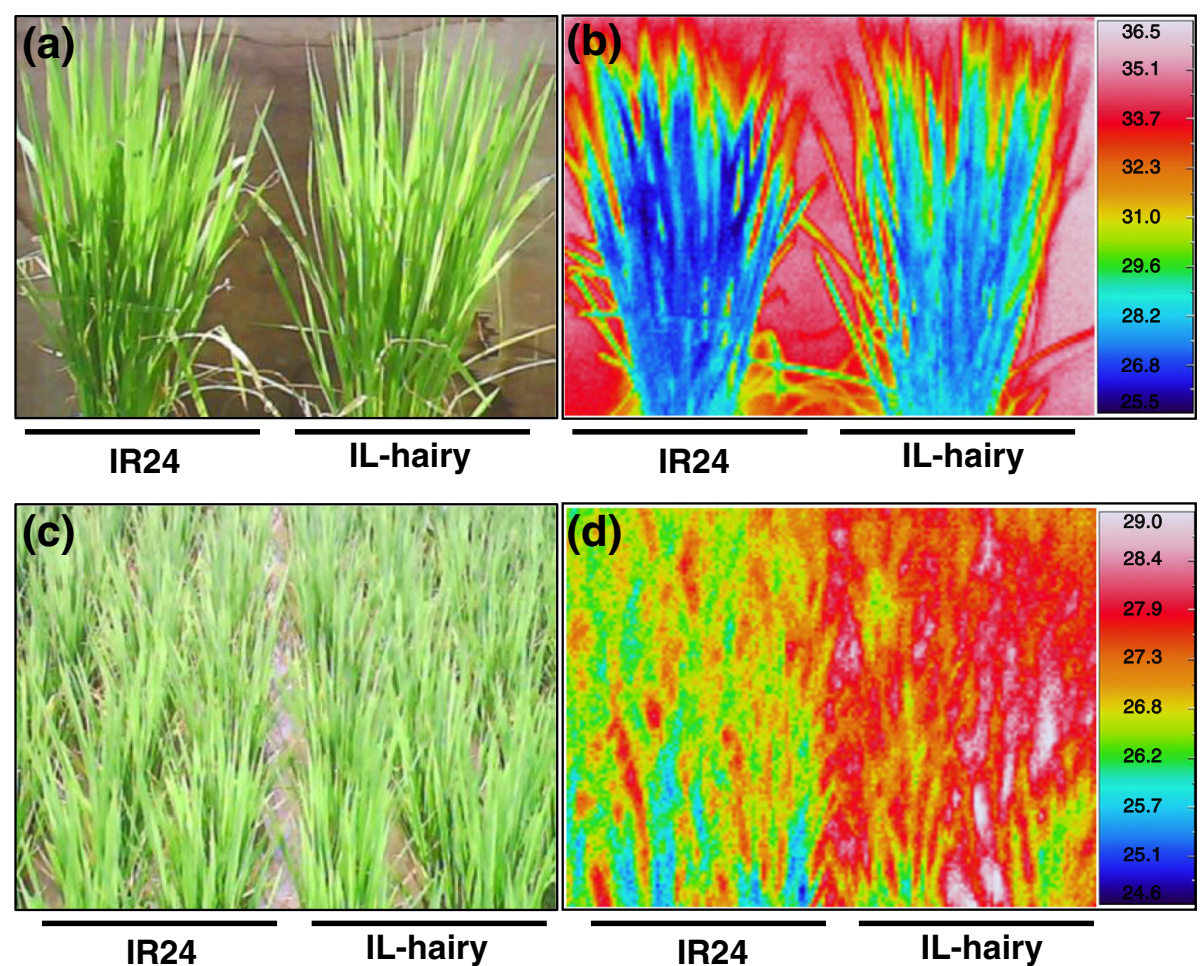

Fig. 3 Visible and thermal images of IR24 and IL-hairy grown in pots $(\mathbf{a}, \mathbf{b})$ and in the field (c, d) at booting stage

information on the genetic basis for high WUE. The hairy leaf trait offers a clue.

A number of QTLs and genes related to leaf hair development have been identified through the use of molecular markers in Arabidopsis (Larkin et al. 1999; Payne et al. 2000; Graham et al. 2006), wheat (Taketa et al. 2002; Dobrovolskaya et al. 2007), and soybean (Du et al. 2009). We identified $B K L$ from IRGC105715 between markers RM3567 and RM7243 on chromosome 6, and it co-segregated with marker RM30 (Fig. 1f). Among previously reported genes related to leaf hair development, we found GL6, related to pubescence growth and development, which was fine-mapped on chromosome 6 (Zeng et al. 2013), and Hla, related to long hair production, which was mapped on chromosome 6 by classical linkage analysis and may be complementary with $\mathrm{Hlb}$ (Nagao et al. 1960). The BKL locus might be the same as that of GL6 or Hla.

\section{Predicted genes in $B K L$ region}

In the candidate region between markers RM3567 and $R M 7243$, 204 genes are annotated in the Nipponbare reference sequence in the Rice Annotation Project Database (RAP-DB, http://rapdb.dna.affrc.go.jp; Sakai et al. 2013) (Additional file 5: Table S4). Among them, five were possible candidates as the causal gene for $B K L$, since their homologs in Arabidopsis thaliana are associated with trichome formation.

Os06g0646600 is classified in a class II KNOTTEDlike homeobox (KNOX) subfamily of rice homeobox genes (Jain et al. 2008). The rice homeobox gene family is divided into zinc finger homeodomain (ZF-HD), homeodomain-leucine zipper protein (HD-ZIP), plant homeodomain (PHD) finger domain, Bell1-like homeobox (BLH), KNOX, and WUS-like homeobox (WOX) subfamilies (Jain et al. 2008). Glabrous Rice 1, which encodes a WOX, regulates micro-hair formation on rice leaves (Li et al. 2012). KNOX-type homeobox genes may be associated with the number of micro-hairs on rice leaves, although involvement of KNOX genes in trichome formation has not been reported in Arabidopsis.

Os06g0649000 showed homology with a WRKY transcription factor (TF), TRANSPARENT TESTA GLABRA2 (TTG2), in Arabidopsis. TTG2 is strongly expressed in trichomes and acts downstream of the trichome initiation genes TTG1 and GLABROUS1. A TTG2-disrupted mutant has no trichomes (Johnson et al. 2002).

Os06g0649500 showed weak homology to TTG1, which encodes a WD40-repeat-containing protein. The TTG1 protein forms a complex with the R2R3-MYB TF GLABRA1 (GL1), the bHLH1 TF GLABRA3 (GL3), and a bHLH2 TF to promote trichome formation in Arabidopsis. 


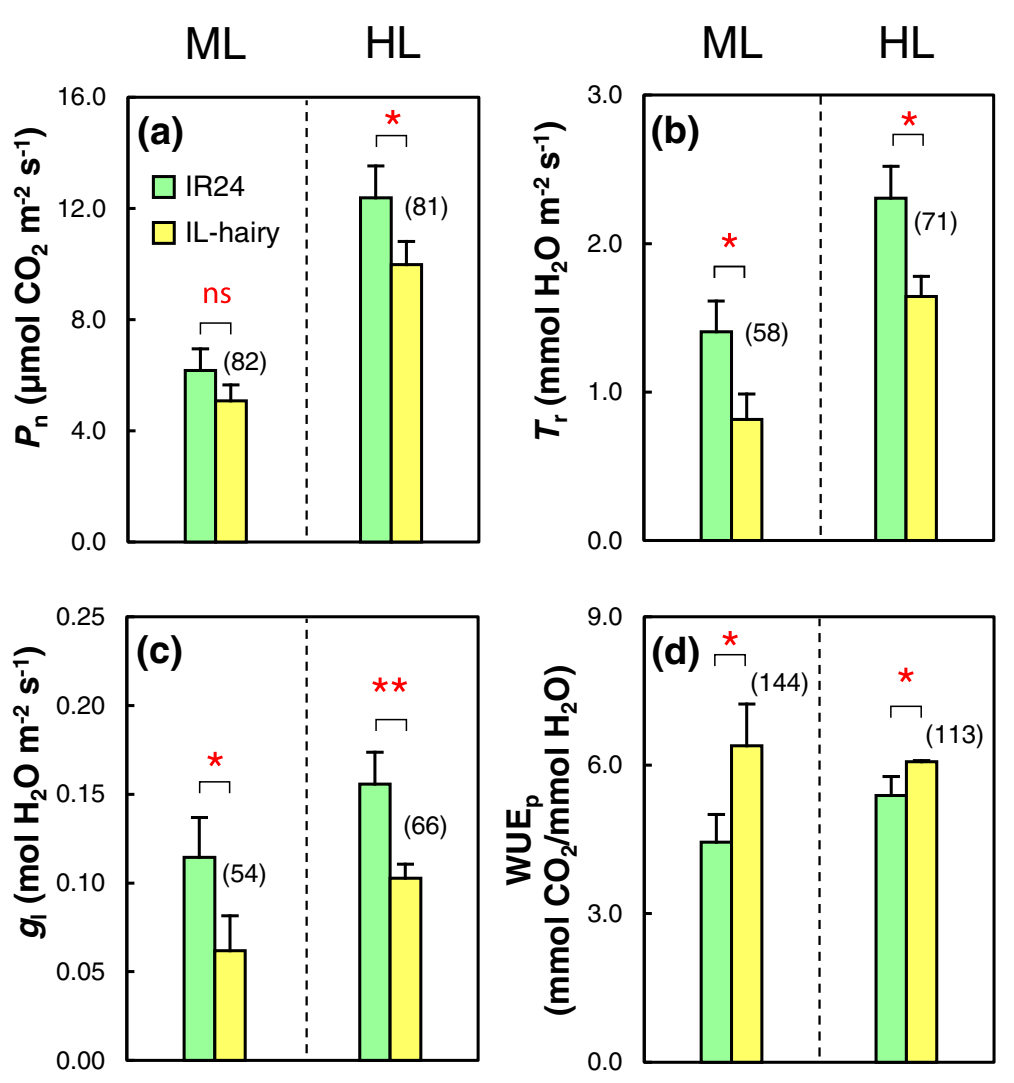

Fig. 4 Photosynthetic traits in IR24 and IL-hairy. Net photosynthetic rate $\left(P_{n} ; \mathbf{a}\right)$, transpiration rate $\left(T_{r} ; \mathbf{b}\right)$, leaf diffusive conductance $\left(g_{j} ; \mathbf{c}\right)$, and photosynthetic water use efficiency (WUE ; d) under moderate (ML: $400 \mu \mathrm{mol} \mathrm{m} \mathrm{m}^{-2} \mathrm{~s}^{-1}$ ) and high light intensity $\left(\mathrm{HL}: 1500 \mu \mathrm{mol} \mathrm{m}^{-2} \mathrm{~s}^{-1}\right.$ ) at booting stage. Data are means $\pm \mathrm{SD}(n=3$ or 4$) .{ }^{*} P=0.05$, ${ }^{*} P=0.01 ; \mathrm{ns}$, not significantly different (t-test). Values in parentheses show percentage of IL-hairy values relative to IR24 values

Os06g0659100 and Os06g0663500 were identified as OSSPL10 and OSSPL11 (SQUAMOSA PROMOTER BINDING PROTEIN-LIKE (SPL) genes in O. sativa), and phylogenetic analysis of $S P L$ genes in rice and Arabidopsis placed OSSPL10 and AtSPL8 in group B, and OsSPL11, AtSPL2, AtSPL10, and AtSPL11 in subgroup A2.2 (Yang et al. 2008). An AtSPL8-knockout mutant obtained by transposon tagging showed disrupted trichome formation (Unte et al. 2003). Transgenic plants expressing a dominant repressor version of SPL10/11/2 formed many trichomes on their cauline leaves and flowers (Shikata et al. 2009).
Although other genes were also possible candidates, the above five genes were the most likely candidates on the basis of the information available at present.

\section{Morphological traits of leaf hair in IL-hairy}

Leaf-hair density was obviously greater in IL-hairy than in IR24 (Figs. 1a-d, 2a, b, e). As the macro-hairs were located on silica cells over small vascular bundles (Fig. 2b-d) and total macro-hair densities on both leaf surfaces did not differ between lines (Table 1), we consider that elongated macro-hairs of IL-hairy are originated from short macro-hairs on small vascular bundles

Table 2 Stomatal density and guard cell length, specific leaf weight, chlorophyll content, and nitrogen content of leaves at the booting stage in IR24 and IL-hairy

\begin{tabular}{|c|c|c|c|c|c|c|c|}
\hline \multirow[t]{2}{*}{ Line } & \multicolumn{2}{|c|}{$\begin{array}{l}\text { Stomatal density } \\
\left(\text { no. } \mathrm{mm}^{-2} \text { ) }\right.\end{array}$} & \multicolumn{2}{|l|}{$\begin{array}{l}\text { Guard cell } \\
\text { length } \\
(\mu \mathrm{m})\end{array}$} & \multirow[t]{2}{*}{$\begin{array}{l}\text { Specific } \\
\text { leaf wt. } \\
\left(\mathrm{g} \mathrm{m}^{-2}\right)\end{array}$} & \multirow[t]{2}{*}{$\begin{array}{l}\text { Chlorophyll } \\
\text { content } \\
\left(\mathrm{g} \mathrm{m}^{-2}\right)\end{array}$} & \multirow[t]{2}{*}{$\begin{array}{l}\text { Nitrogen } \\
\text { content } \\
\left(\mathrm{g} \mathrm{m}^{-2}\right)\end{array}$} \\
\hline & Adaxial & Abaxial & Adaxial & Abaxial & & & \\
\hline IR24 & $472 \pm 16$ & $625 \pm 14$ & $21.1 \pm 0.7$ & $20.8 \pm 0.4$ & $43.9 \pm 1.0$ & $0.41 \pm 0.02$ & $1.38 \pm 0.05$ \\
\hline \multirow[t]{2}{*}{ IL-hairy } & $469 \pm 9$ & $646 \pm 22$ & $21.1 \pm 0.4$ & $20.9 \pm 0.8$ & $44.7 \pm 1.2$ & $0.39 \pm 0.03$ & $1.29 \pm 0.06$ \\
\hline & $n s^{a}$ & ns & ns & ns & ns & ns & ns \\
\hline
\end{tabular}

Data are means \pm SD $(n=3-4)$. ${ }^{a}$ ns, not significant by Student's $t$-test at $P=0.05$ 
(a)

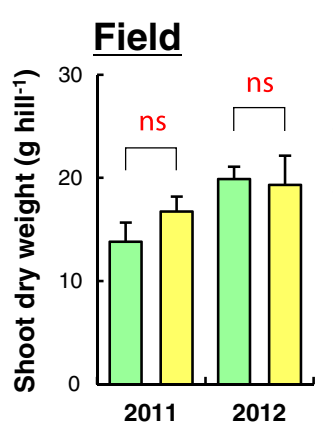

Pot

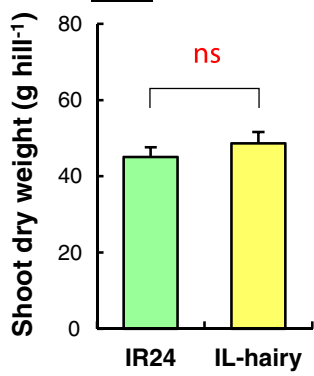

口IR24 口IL-hairy
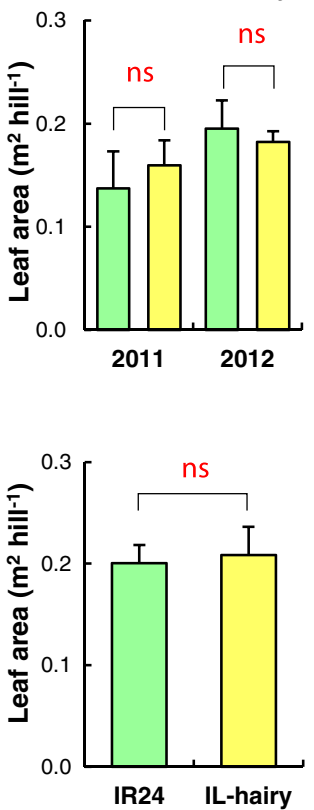

(b)
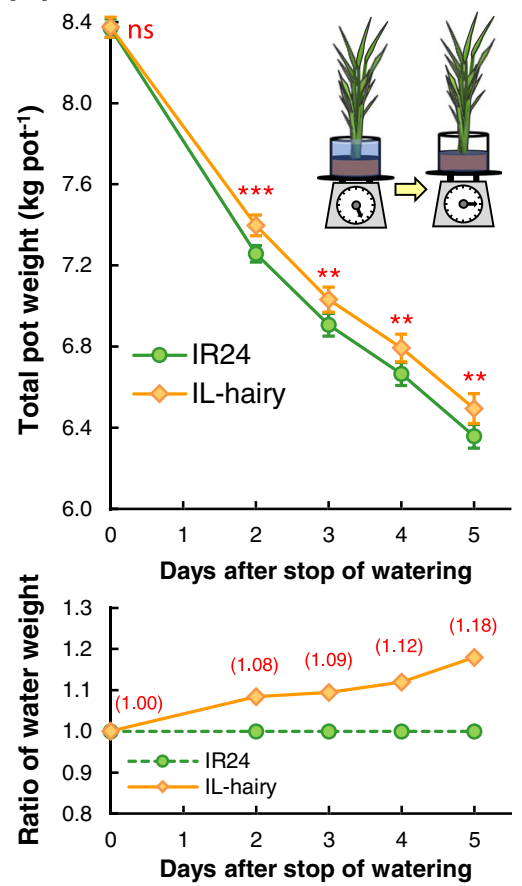

Fig. 5 Shoot dry weigh, leaf area, and water uptake traits of the whole plant. a Shoot dry matter production and leaf area in the field (vegetative stage) and pots (heading stage). Data are means \pm SD (field, $n=3$; pot, $n=4$ ). ns, not significantly different (t-test). $\mathbf{b}$ Changes of total pot weight including plant weight and ratio of water weight of IL-hairy relative to that of IR24 during 5 days after stop of watering at the booting stage. Data are means $\pm \mathrm{SD}(n=7) .{ }^{* *} P=0.01,{ }^{* * *} P=0.001 ; \mathrm{ns}$, not significantly different (t-test). Values in parentheses show relative values of IL-hairy to IR24

found in IR24, and $B K L$ functions in the elongation of macro-hairs through epidermal cell differentiation. As dense leaf hairs were observed from the sixth-leaf stage, $B K L$ acts at least from this stage.

On the other hand, glabrous rice varieties which show the reduction or absence of macro-hair on the surface of the hulls and leaves have been widely cultivated in several countries such as the United State and Australia (Rutger and Mackill 2001). These glabrous varieties are known to generate less dust during processing than pubescent varieties (Jodon 1965). In our observation, hull hairiness did not differ between IR24 and IL-hairy (Additional file 3: Fig. S1). Therefore, $B K L$ does not affect macro-hair development on surface of hull.

Morphological traits of leaf hairs depend on species. For instance, Arabidopsis has branched hairs (trichomes) (Larkin et al. 1999), whereas wheat (Triticum aestivum L.) has long and short simple hairs (Taketa et al. 2002). It is well known that phytohormones control leaf hair development. In wheat, cytokinin and jasmonate (JA) increase the density of leaf hairs, and cytokinin also increases hair length (Kobayashi et al. 2012). In rhodes grass (Chloris gayana Kunth), JA increases the density of macro-hairs and affects trichome initiation (Kobayashi et al. 2010). JA ZIM-domain (JAZ) proteins repress JAregulated anthocyanin accumulation and trichome initiation with interaction to the WD40-repeat/bHLH/ MYB transcriptional complexes (Qi et al. 2011). These protein complexes contain GL1, GL3, TTG3, and EGL3 protein subunits, which showed homologous relationships to the predicted protein encoded in the candidate $B K L$ region. As one or more phytohormones may participate in the promotion of leaf hair development by $B K L$, further studies will need to investigate them.

\section{Photosynthetic and growth traits of IL-hairy}

IL-hairy provides a unique opportunity to examine the effects of a morphological character on physiological traits, because its genetic background is almost the same as that of IR24. IL-hairy had lower $P_{\mathrm{n}}, T_{\mathrm{r}}$, and $g_{1}$ than IR24 under both moderate and high light intensities (Fig. $4 \mathrm{a}-\mathrm{C}$ ), but $T_{\mathrm{r}}$ and $g_{1}$ were reduced more greatly than $P_{\mathrm{n}}$ in IL-hairy. As a result, $\mathrm{WUE}_{\mathrm{p}}$ was higher in IL-hairy than in IR24 (Fig. 4d). We detected no differences in size and density of stomata, SLW, chlorophyll content, and nitrogen content of leaves between the two lines (Table 2). These facts indicate that $B K L$ did not affect these morphological and physiological traits. Altogether, it is suggested that leaf hairs cause the increase in $\mathrm{WUE}_{\mathrm{p}}$ through restraint of transpiration by increasing the boundary layer resistance. Shading sunlight by the hairs might partially reduce photosynthesis of IL-hairy. Generally, 
plants prevent excessive rise of leaf temperature by evaporative heat loss in the process of transpiration. Our results showed that leaf temperature at both plant and canopy levels was higher in IL-hairy than in IR24 (Fig. 3b, d). These results support the explanation that evaporative heat loss is reduced by the increased boundary layer resistance in ILhairy. However, strict evaluation of boundary layer resistance in IL-hairy will be required. In addition, further studies should be made to know whether the relationship between WUEp and leaf hairiness is affected by environmental factors influencing Tr.

Shoot dry weight, leaf area, and other growth traits in both field and pot trials did not significantly differ between IL-hairy and IR24 (Fig. 5a, Additional file 4: Table S3). In the experiment on the change of pot weight after stop of watering, IL-hairy took up less water than IR24 (Fig. 5b). These results indicate that the leaf-hair trait mediated by $B K L$ did not significantly affect biomass productivity, although $P_{\mathrm{n}}$ of IL-hairy was marginally lower than that of IR24 (Fig. 4a), and leaf hairs might improve not only WUE $\mathrm{Wut}_{\mathrm{p}}$ also plant WUE.

We were able to determine the relationship between a morphological trait mediated by a single gene and physiological traits. The photosynthetic traits of IL-hairy, with a high $\mathrm{WUE}_{\mathrm{p}}$, may be useful for improving drought tolerance and for reducing water inputs in rice cropping. The next step is to evaluate the effect of leaf hairiness on $W_{\mathrm{W}}$, plant WUE, and biomass productivity at the individual plant and canopy levels under water deficiency.

\section{Conclusions}

We identified the BLANKET LEAF hairy-leaf gene from wild Oryza nivara. BKL is tightly linked to SSR marker RM30 on chromosome 6 , and appears to cause the elongation of macro-hairs. The hairy-leaf trait increased leaf surface temperature and $\mathrm{WUE}_{\mathrm{p}}$ by restricting leaf transpiration. These traits may be useful in the development of rice cultivars adapted to water-saving cultivation systems.

\section{Methods}

\section{Plant materials}

A $\mathrm{BC}_{1} \mathrm{~F}_{1}$ population was developed from a cross between O. nivara IRGC105715, an annual wild accession from Cambodia, and O. sativa ssp. indica 'IR24', as the recurrent parent (Additional file 6: Fig. S2). Plants were backcrossed to IR24 to develop the $\mathrm{BC}_{4} \mathrm{~F}_{1}$ generation. Self-pollination was used to develop the $\mathrm{BC}_{4} \mathrm{~F}_{4}$ generation. $\mathrm{A} \mathrm{BC}_{4} \mathrm{~F}_{4}$ introgression line (IL) with hairy leaves was named IL-hairy (Fig. 1c, d). IL-hairy was backcrossed with IR24 to develop the $\mathrm{BC}_{5} \mathrm{~F}_{1}$ generation. The $\mathrm{BC}_{5} \mathrm{~F}_{1}$ plants were self-pollinated, and $189 \mathrm{BC}_{5} \mathrm{~F}_{2}$ plants were used to detect the location of the gene for hairy leaf. The subsequent $189 \mathrm{BC}_{5} \mathrm{~F}_{3}$ lines were evaluated for leaf hairiness in a progeny test.
The $\mathrm{BC}_{5} \mathrm{~F}_{2}$ and $\mathrm{BC}_{5} \mathrm{~F}_{3}$ populations were grown in the paddy field of Kyushu University's farm $\left(33^{\circ} 37^{\prime} \mathrm{N}, 130^{\circ}\right.$ $27^{\prime} \mathrm{E}$ ) in the summer of 2013 and 2014, respectively. Each row contained 12 hills. Both populations were evaluated for leaf hairiness at the tillering stage. To evaluate physiological and morphological traits, we also grew plants outdoors in 8 -L pots (one seedling per pot) filled with sandy loam in summer 2013. Pots received $1.0 \mathrm{~g} \mathrm{~N}$ as ammonium sulfate, $1.6 \mathrm{~g} \mathrm{P}$ as calcium superphosphate, and $1.6 \mathrm{~g} \mathrm{~K}$ as potassium chloride as basal fertilizer; no additional fertilizer was applied. Sufficient water was supplied throughout.

\section{Genetic analysis}

For genotyping using SSR markers, total genomic DNA was extracted from freeze-dried leaf tissue of the $F_{2}$ population according to Dellaporta et al. (1983), with minor modifications. Polymerase chain reaction (PCR) analysis was performed in a $15 \mu \mathrm{L}$ reaction mixture containing $50 \mathrm{mM} \mathrm{KCl}, 10 \mathrm{mM}$ Tris $\cdot \mathrm{HCl}$ (pH 9.0), $1.5 \mathrm{mM}$ $\mathrm{MgCl}_{2}, 200 \mu \mathrm{M}$ each dNTP, $0.2 \mu \mathrm{M}$ each primer, 0.75 units Taq polymerase (Takara, Otsu, Japan), and approximately $25 \mathrm{ng}$ of template DNA in a GeneAmp PCR system 9700 (Applied Biosystems, Foster City, CA, USA). The thermal cycler was programmed for a first denaturation step of $5 \mathrm{~min}$ at $95{ }^{\circ} \mathrm{C}$, followed by 35 cycles of $95{ }^{\circ} \mathrm{C}$ for $30 \mathrm{~s}, 55^{\circ} \mathrm{C}$ for $30 \mathrm{~s}$, and $72{ }^{\circ} \mathrm{C}$ for $30 \mathrm{~s}$. PCR products were separated in $4 \%$ agarose gels (Agarose HT; Amresco Inc., Solon, OH, USA) in $0.5 \times$ TBE buffer. Chromosomal segments from IRGC105715 introgressed in the backcrossed progeny were detected using 93 rice SSR markers published in McCouch et al. (2002) and Chen et al. (1997) and one SSR marker originally designed in this study (Additional file 1: Table S1). Recombination values between markers were estimated by the maximum-likelihood equation (Allard 1956) using Kosambi's mapping function (Kosambi 1944).

\section{Phenotyping of hairy-leaf trait in the field}

At the tillering stage, individual $\mathrm{BC}_{5} \mathrm{~F}_{2}$ plants grown in the field were directly examined to determine the presence of leaf hairs on the adaxial surface of the topmost fully expanded leaf on the main stem. Plants were scored as 'normal-leaf' if they had only a few hairs (IR24 type) or 'hairy-leaf' (IL-hairy type) for linkage analysis. The phenotypes of $\mathrm{BC}_{5} \mathrm{~F}_{3}$ lines (IR24 type, segregating type, and IL-hairy type) were used for mapping of the hairyleaf gene locus.

\section{Microscopic observations of leaf hairs and stomatal traits} Samples from the middle of leaf blades were fixed in formalin-acetic acid-alcohol (FAA) solution for at least 3 days. They were incubated in four changes of $70 \%$ ethanol at $80{ }^{\circ} \mathrm{C}$ for $12 \mathrm{~h}$ each, then in two changes of 
$80 \%$ lactic acid at $80{ }^{\circ} \mathrm{C}$ for $12 \mathrm{~h}$, and finally cleared in saturated chloral hydrate solution for at least $24 \mathrm{~h}$. The leaf hair and stomata on each side of the leaf were observed under a light microscope (Axioplan; Zeiss, Jena, Germany). Four square areas $\left(1.5 \times 4 \mathrm{~mm}^{2}\right)$ on each surface were analyzed for the quantification of leaf hair density $(50 \times)$, macro-hair density $(50 \times)$, guard cell length $(200 \times)$, and stomatal density $(200 \times)$. Stomata were photographed with a digital camera (DXM1200F; Nikon, Tokyo, Japan), and 400x images of each surface in triplicate were used to measure guard cell length.

\section{Scanning electron microscopy}

For scanning electron microscopic observation of leaf hairs, fully expanded leaves on the main stem grown in the field were sampled at 38 days after transplanting (tillering stage), washed in distilled water, air-dried, and sputter-coated with gold. The leaf surface was observed by scanning electron microscopy (JEOL JSM-5200; Mamiya Co., Ltd., Japan).

\section{Measurement of leaf temperature}

Leaf temperature was measured with a portable infrared thermal camera (F30; NEC Abio, Tokyo, Japan) with a resolution of $0.1{ }^{\circ} \mathrm{C}$ and viewing angles of $28^{\circ}$ horizontal and $21^{\circ}$ vertical. In the field, the camera was set about $1 \mathrm{~m}$ above the sunlit leaf surface.

\section{Measurement of photosynthetic gas exchange and leaf sampling}

Photosynthetic gas exchange of the topmost fully expanded leaf on the main stem of potted plants was measured with an open gas exchange system at the booting stage. The gas exchange rate was measured with a sandwich-type assimilation chamber, equipped with a fan for mixing air (PLC-4B; ADC, Hoddesdon, UK). The air temperature in the assimilation chamber was controlled by circulating temperature-controlled water to a radiator attached to the chamber. The air had been moisture-saturated at $21.5 \mathrm{C}^{\mathrm{O}}$ by a dew point generator before it was sent to the assimilation chamber. The air with controlled humidity was pumped into the chamber at a rate of $16.7 \mathrm{~cm}^{3} \mathrm{~s}^{-1}$, adjusted with a mass air flow regulator. The measurement was carried out under the conditions of $27.9 \pm 0.4{ }^{\circ} \mathrm{C}$ in air temperature, $387 \pm 3 \mu \mathrm{L}$ $\mathrm{CO}_{2} \mathrm{~L}^{-1}$ in ambient $\mathrm{CO}_{2}$ concentration, and $68 \pm 1.5 \%$ relative humidity in the chamber. The leaf area was $5.9 \mathrm{~cm}^{2}$. Light was provided by a metal halide lamp (LSM180; Sumita Optical Glass Inc., Japan) at a photosynthetic photon flux density of 400 (ML) or $1500 \mu \mathrm{mol} \mathrm{m}$ ${ }^{-2} \mathrm{~s}^{-1}$ (HL). The $\mathrm{CO}_{2}$ concentration and water vapor pressure in the reference and sample air volumes were monitored with an infrared gas analyzer (Li-6262; LICOR, Lincoln, NE, USA) and used to calculate $P_{\mathrm{n}}$ and
$T_{\mathrm{r}}$ as described by Long and Hallgren (1985). WUE $\mathrm{W}_{\mathrm{p}}$ was calculated as $P_{\mathrm{n}} / T_{\mathrm{r}}$. During measurement of gas exchange, leaf and air temperature were also measured by thermocouple for evaluating $g_{1} \cdot g_{1}$ to water vapor transfer was calculated as described by Gaastra (1959).

Specific leaf weight, chlorophyll content, and nitrogen content of the same leaves used for gas exchange measurement were measured. The chlorophyll content of leaves was determined by a spectrophotometer (UV-1200; Shimadzu, Kyoto, Japan) according to the method of Wintermans and de Mots (1965). Leaf samples were oven-dried at $80{ }^{\circ} \mathrm{C}$ for at least 2 days and weighed. The leaf nitrogen content of dried samples was quantified by a mass spectrometer (ANCA-SL; Europa Scientific, Franklin, USA).

\section{Growth traits and water uptake}

To evaluate dry matter production and leaf area, ILhairy and IR24 were grown in the paddy field (one seedling per hill; spacing $25 \mathrm{~cm} \times 25 \mathrm{~cm}$ ) in 2011 and 2012 . Seedling at fifth-leaf stage were transplanted at a rate of 16 hills $\mathrm{m}^{-2}$ (spacing $25 \mathrm{~cm} \times 25 \mathrm{~cm}$ ) with one plant per hill. As a basal fertilizer, chemical fertilizer was applied at a rate of $5.0 \mathrm{~g} \mathrm{~N}, 12.0 \mathrm{~g} \mathrm{P}$ and $12.0 \mathrm{~g} \mathrm{~K} \mathrm{~m}^{-2}$ in form of ammonium sulfate, calcium superphosphate and potassium chloride, respectively. The plots were randomly arranged with three replicates. Plants were also grown outdoor in $8-\mathrm{L}$ pots filled with paddy soil $(5.0 \mathrm{~kg} \mathrm{DW})$ and compound fertilizer containing $0.35 \mathrm{~g} \mathrm{~N}, 0.35 \mathrm{~g} \mathrm{P}$ and $0.35 \mathrm{~g}$ K. Plant shoots were sampled at 28 days after transplanting in the field experiment and at heading stage in the pot experiment. Subsequently, the leaf area was measured by use of an automatic area meter (AAM8; Hayashi-denko, Tokyo, Japan), and then the samples were oven-dried at $80{ }^{\circ} \mathrm{C}$ for 3 days to determine dry weight. In addition, plant height, tiller number, leaf age, and SPAD value (SPAD-502; Konica Minolta Sensing, Japan) were measured at the 28 days after transplanting in 2011. For evaluating grain phenotypes, grains of IR24 and IL-hairy were photographed with digital camera and measured grain length and width by caliper.

To compare water diminution by transpiration from plant between IL-hairy and IR24, plants were grown in 8-L pots filled with paddy soil $(5.0 \mathrm{~kg} \mathrm{DW})$ containing $1.0 \mathrm{~g} \mathrm{~N}, 0.5 \mathrm{~g} \mathrm{P}$ and $0.5 \mathrm{~g} \mathrm{~K}$ in form of urea, calcium superphosphate and potassium chloride, respectively, in a greenhouse under natural sunlight. Water diminution per pot was evaluated at booting stage. Total pot weight including plant was adjusted $8.4 \mathrm{~kg}$ by water (approx. $2.8 \mathrm{~kg}$ ). Then, plant weight was approx. $0.3 \mathrm{~kg}$. Subsequently, the plants of pots were withheld for irrigation during five consecutive clear days. Pot weight was measured every day at the same time to estimate the water diminution (the total amount of transpiration from the 
plant and evaporation from water surface of the pot) per day. In this estimation, we postulated that the water loss from water surface is the same in all pots of IL-hairy and IR24. As there were no significant differences in shoot dry weight and leaf area between the two lines (Fig. 5a), the difference in total pot weight between the two lines reflects that in the leaf-hair development. Water weight per pot was estimated by subtracting weight of soil, pot, and plant from total pot weight, and ratio of water weight of IL-hairy relative to that of IR24 was calculated.

\section{Additional files}

Additional file 1: Table S1. List of primers for SSR markers used in this study. (XLSX $25 \mathrm{~kb}$ )

Additional file 2: Table S2. Segregation of the hairy leaf trait in the $\mathrm{BC}_{5} \mathrm{~F}_{3}$ populations derived from a cross between IR24 and IL-hairy. (XLSX $16 \mathrm{~kb})$

Additional file 3: Figure S1. Grain phenotypes. a Phenotype of hull surface in IR24 and IL-hairy. Scale bar, $5 \mathrm{~mm}$. b, c Grain length (b) and grain width (c) of IR24 and IL-hairy. Data are means \pm SD $(n=10)$. ns, not significantly different (t-test). (PPTX $107 \mathrm{~kb}$ )

Additional file 4: Table S3. Growth traits of IR24 and IL-hairy grown under the field at the tilling stage. (XLSX $16 \mathrm{~kb}$ )

Additional file 5: Table S4. Gene annotation by RAP-DB in BKL region. (XLSX $29 \mathrm{~kb}$ )

Additional file 6: Figure S2. Breeding scheme for the plant materials used in this study. (PPTX $38 \mathrm{~kb}$ )

\section{Abbreviations}

BLH: Bell1-like homeobox; DW: Dry weight; gi: Leaf diffusive conductance HD-ZIP: Homeodomain-leucine zipper protein; HL: High light intensity; IL: Introgression line; JA: Jasmonate; KNOX: KNOTTED-like homeobox; ML: Moderate light intensity; PHD: Plant homeodomain; $P_{n}$ : Net photosynthetic rate; QTL: Quantitative trait locus; SLW: Specific leaf weight; SSR: Simple sequence repeats; $T_{r}$ : Transpiration rate; WOX: WUS-like homeobox; WUE: Water use efficiency; WUEp: Photosynthetic water use efficiency; ZF-HD: Zinc finger homeodomain

\section{Acknowledgement}

This work was supported by a grant from the Japan Science and Technology Agency - Japan International Cooperation Agency within the framework of the Science and Technology Research Partnership for Sustainable Development (SATREPS) to AY. The Canon foundation also supported this research to HY. We are grateful to Prof. T. Mochizuki, Agroecology Laboratory, Faculty of Agriculture, Kyushu University, for use of the infrared thermal imager.

\section{Availability of data and materials}

The datasets supporting the conclusions of this article are included within the article and its additional files.

\section{Authors' contributions}

$\mathrm{NH}, \mathrm{TA}$, and $\mathrm{AY}$ designed the study. $\mathrm{NH}$ conducted all experiments. $\mathrm{Yl}, \mathrm{HY}$, and $\mathrm{NH}$ developed plant materials. NF performed technical support for scanning electron microscopy observation. YY supported genetic analysis. TA and OU helped revise the paper. All authors read and approved the final manuscript.

\section{Competing interests}

The authors have no conflicts of interest to declare.

\section{Publisher's Note}

Springer Nature remains neutral with regard to jurisdictional claims in published maps and institutional affiliations.

\section{Author details}

${ }^{1}$ Faculty of Agriculture, Kyushu University, 6-10-1 Hakozaki, Higashi-ku, Fukuoka 812-8581, Japan. ${ }^{2}$ Faculty of Agriculture, Ehime University, Tarumi, Matsuyama, Ehime 790-8566, Japan.

Received: 30 November 2016 Accepted: 4 May 2017

Published online: 12 May 2017

\section{References}

Allard RW (1956) Formulas and tables to facilitate the calculation of recombination values in heredity. Hilgardia 24:235-278

Bernier J, Kumar A, Serraj R, Spaner D, Atlin G (2008) Breeding upland rice for drought resistance. J Sci Food Agric 88:927-939

Chen X, Temnykh S, Xu Y, Cho Y, McCouch S (1997) Development of a microsatellite framework map providing genome-wide coverage in rice (Oryza sativa L.). Theor Appl Genet 95:553-567

Condon AG, Richards RA, Rebetzke J, Farquhar GD (2004) Breeding for high water-use efficiency. J Exp Bot 55:2447-2460

Dellaporta SL, Wood J, Hicks JB (1983) A plant DNA mini-preparation: Version II. Plant Mol Biol Rep 1:19-21

Ding XP, Li XK, Xiong LZ (2011) Evaluation of near-isogenic lines for drought resistance QTL and fine mapping of a locus affecting flag leaf width, spikelet number, and root volume in rice. Theor Appl Genet 123:815-826

Dobrovolskaya O, Pshenichnikova TA, Arbuzova VS, Lohwasser U, Röder MS, Börner A (2007) Molecular mapping of genes determining hairy leaf character in common wheat with respect to other species of the Triticeae. Euphytica 155:285-293

Du WJ, Fu SX, Yu DY (2009) Genetic analysis for the leaf pubescence density and water status traits in soybean [Glycine max (L.) Merr.]. Plant Breed 128:259-265

Gaastra P (1959) Photosynthesis of crop plants as influenced by light, carbon dioxide, temperature, and stomatal diffusion resistance. Mededelingen van de Landbouhoogeschool te Wageningen, Nederland 59:1-68

Graham J, Smith K, Tierney I, Mackenzie K, Hackett CA (2006) Mapping gene $\mathrm{H}$ controlling cane pubescence in raspberry and its association with resistance to cane botrytis and spur blight, rust and cane spot. Theor Appl Genet 112:818-831

Hamid A, Agata W, Kawamitsu Y (1990) Photosynthesis, transpiration and water use efficiency in four cultivars of mungbean, Vigna radiata (L.) Wilczek. Photosynthetica 24:96-101

Heitholt JJ (1989) Water use efficiency and dry matter distribution in nitrogen and water-stressed winter wheat. Agron J 81:464-469

Jain M, Tyagi AK, Khurana JP (2008) Genome-wide identification, classification, evolutionary expansion and expression analyses of homeobox genes in rice. FEBS J 275:2845-2861

Jodon NE (1965) Four morphologic characters in rice. Inheritance and relation to yield and height of awned, glabrous, liguleless and long-glumed. Heredity 56:119-125

Johnson CS, Kolevski B, Smyth DR (2002) TRANSPARENT TESTA GLABRA2, a trichome and seed coat development gene of Arabidopsis, encodes a WRKY transcription factor. Plant Cell 14:1359-1375

Johnson HB (1975) Plant pubescence: an ecological perspective. Bot Rev 41: $233-258$

Kamoshita A, Chandra BR, Boopathi NM, Fukai S (2008) Phenotypic and genotypic analysis of drought-resistance traits for development of rice cultivars adapted to rainfed environments. Field Crops Res 109:1-23

Kato Y, Hirotsu S, Nemoto K, Yamagishi J (2008) Identification of QTLs controlling rice drought tolerance at seedling stage in hydroponic culture. Euphytica 160:423-430

Kinoshita T (1995) C. Report of committee on gene symbolization, nomenclature and linkage groups. Rice Genet Newsl 12:9-153

Kobayashi H, Yanaka M, lkeda TM (2010) Exogenous methyl jasmonate alters trichome density on leaf surfaces of rhodes grass (Chloris gayana Kunth). J Plant Growth Regul 29:506-511

Kobayashi H, Yanaka M, Ikeda TM (2012) 6-Benzylaminopurine treatment induces increased pubescence on wheat leaves. Plant Growth Regul 67:19-25 
Kosambi D (1944) The estimation of map distance from recombination values. Ann Eugen 12:172-175

Lande R (2009) Adaptation to an extraordinary environment by evolution of phenotypic plasticity and genetic assimilation. J Evol Biol 22:1435-1446

Larkin JC, Walker JD, Bolognesi-Winfield AC, Gray JC, Walker AR (1999) Allelespecific interactions between ttg and gl1 during trichome development in Arabidopsis thaliana. Genetics 151:1591-1604

Lawson T, Blatt M (2014) Stomatal size, speed and responsiveness impact on photosynthesis and water use efficiency. Plant Physiol 164:1556-1570

Levin DA (1973) The role of trichomes in plant defence. Q Rev Biol 48:3-15

Li W, Wu J, Weng S, Zhang D, Zhang Y, Shi C (2010) Characterization and fine mapping of the glabrous leaf and hull mutants $(g / 1)$ in rice (Oryza sativa L.). Plant Cell Rep 29:617-627

Li J, Yuan Y, Lu Z, Yang L, Gao R, Lu J, Xiong G (2012) Glabrous Rice 1, encoding a homeodomain protein, regulates trichome development in rice. Rice 5:32

Long SP, Hallgren JE (1985) Measurements of $\mathrm{CO}_{2}$ assimilation by plants in the field and the laboratory. In: Coombs J, Hall DO, Long SP, Scurlock JMO (eds) Techniques in Bioproductivity and Photosynthesis. Pergamon Press, Oxford, pp 62-94

McCouch SR, Teytelman L, Xu YB, Lobos KB, Clare K, Walton M, Fu BY, Maghirang R, Li ZK, Xing YZ, Zhang QF, Kono I, Yano M, Fjellstrom R, Declerck G, Schneider D, Cartinhour S, Ware D, Stein L (2002) Development and mapping of 2240 new SSR markers for rice (Oryza sativa L.). DNA Res 9:199-207

Maclean J, Hardy B, Hettel G (2013) Rice Almanac: Source Book for the Most Important Economic Activities on Earth, 4th edn. IRRI, Los Banos

Nagao S, Takahashi M (1963) Trial construction of twelve linkage groups in Japanese rice. Genetical studies on rice plant. XXVII. J Fac Agr Hokkaido Univ 53:72-130

Nagao S, Takahashi M-E, Kinoshita T (1960) Genetical studies on rice plant XXV. Inheritance of three morphological characters, pubescence of leaves and floral glumes, and deformation of empty glumes. J Fac Agr Hokkaido Univ 51:299-314

Nicotra AB, Atkin OK, Bonser SP, Davidson AM, Finnegan EJ, Mathesius U, Poot P, Purugganan MD, Richards CL, Valladares F, Vankleunen M (2010) Plant phenotypic plasticity in a changing climate. Trends Plant Sci 15:684-692

Payne CT, Zhang F, Lloyd AM (2000) GL3 encodes a bHLH protein that regulates trichome development in Arabidopsis through interaction with GL1 and TTG1. Genetics 156:1349-1362

Peng S, Krieg DR (1992) Gas exchange traits and their relationship to water use efficiency of grain sorghum. Crop Sci 32:386-391

Pfeiffer T, Peyyala WR, Ren Q, Ghabrial AS (2003) Increased soybean pubescence density: yield and soybean mosaic virus resistance effects. Crop Sci 43:2071-2076

Price AH, Cairns JE, Horton P, Jones HG, Griffiths H (2002) Linking droughtresistance mechanisms to drought avoidance in upland rice using a QTL approach: progress and new opportunities to integrate stomatal and mesophyll responses. J Exp Bot 53:989-1004

Qi T, Song S, Ren Q, Wu D, Huang H, Chen Y, Fan M, Peng W, Ren C, Xie D (2011) The Jasmonate-ZIM-domain proteins interact with the WD-Repeat/ $\mathrm{bHLH} / \mathrm{MYB}$ complexes to regulate Jasmonate-mediated anthocyanin accumulation and trichome initiation in Arabidopsis thaliana. Plant Cell 23: 1795-1814

Rutger JN, Mackill DJ (2001) Application of Mendelian genetics in rice breeding. In: Khush GV, Brar DS, Hardy B (eds) Rice Genetics IV, Proceedings of the Fourth International Rice Genetics Symposium, Los Baños, Philippines, October 2000. International Rice Research Institute, Philippines, p 29

Sakai H, Lee SS, Tanaka T, Numa H, Kim J, Kawahara Y, Wakimoto H, Yang CC, Iwamoto M, Abe T, Yamada Y, Muto A, Inokuchi H, Ikemura T, Matsumoto T, Sasaki T, Itoh T (2013) Rice Annotation Project Database (RAP-DB): an integrative and interactive database for rice genomics. Plant Cell Physiol 54:e6

Shikata M, Koyama T, Mitsuda N, Ohme-Takagi M (2009) Arabidopsis SBP-Box Genes SPL10, SPL11 and SPL2 control morphological change in association with shoot maturation in the reproductive phase. Plant Cell Physiol 50:2133-2145

Symonds W, Godoy AV, Alconada T, Botto JF, Juenger TE, Casal JJ, Lloyd AM (2005) Mapping quantitative trait loci in multiple populations of Arabidopsis thaliana identifies natural allelic variation for trichome density. Genetics 169 : 1649-1658

Takai T, Ohsumi A, San-Oh Y, Rebecca M, Laza C, Kondo M, Yamamoto T, Yano M (2009) Detection of a quantitative trait locus controlling carbon isotope discrimination and its contribution to stomatal conductance in japonica rice. Theor Appl Genet 118:1401-1410
Taketa S, Chang CL, Ishii M, Takeda K (2002) Chromosome arm location of the gene controlling leaf pubescence of a Chinese local wheat cultivar 'Hongmang-mai'. Euphytica 125:141-147

This D, Comstock J, Courtois B, Xu Y, Ahmadi N, Vonhof WM, Fleet C, Setter T, McCouch S (2010) Genetic analysis of water use efficiency in rice (Oryza sativa L.) at the leaf level. Rice 3:72-86

Unte US, Sorensen AM, Pesaresi P, Gandikota M, Leister D, Saedler H, Huijser P (2003) SPL8, an SBP-box gene that affects pollen sac development in Arabidopsis. Plant Cell 15:1009-1019

Wada Y (2002) Comparison of light photosynthesis curves between IRAT109, a hairy upland rice cultivar and IRAT212, a non-hairy upland rice cultivar. Jpn J Crop Sci 71(2):158-159

Wintermans JFGA, de Mots M (1965) Spectrophotometric characteristics of chlorophyll and their pheophytins in ethanol. Biochim Biophys Acta 109:44-45

Wright IJ, Reich PB, Westoby M, Ackerly DD, Baruch Z, Bongers F, Cavender-Bares J, Chapin T, Cornelissen JHC, Diemer M, Flexas J, Garnier E, Groom PK, Gulias J, Hikosaka K, Lamont BB, Lee T, Lee W, Lusk C, Midgley JJ, Navas M-L, Niinemets U, Oleksyn J, Osada N, Poorter H, Poot P, Prior L, Pyankov VI, Roumet C, Thomas SC, Tjoelker MG, Veneklaas EJ, Villar R (2004) The worldwide leaf economics spectrum. Nature 428:821-827

Xu Y, This D, Pausch RC, Vonhof WM, Coburn JR, Comstock JP, McCouch SR (2009) Leaf-level water use efficiency determined by carbon isotope discrimination in rice seedlings: genetic variation associated with population structure and QTL mapping. Theor Appl Genet 118:1065-1081

Yang Z, Wang W, Gu S, Hu Z, Xu H, Xu C (2008) Comparative study of SBP-box gene family in Arabidopsis and rice. Gene 407:1-11

Yonemaru J, Yamamoto T, Fukuoka S, Uga Y, Hori K, Yano M (2010) Q-TARO: QTL Annotation Rice Online Database. Rice 3:194-203

Zeng YH, Zhu YS, Lian L, Xie HG, Zhang JF, Xie HA (2013) Genetic analysis and fine mapping of the pubescence gene $G L 6$ in rice (Oryza sativa L.). Chin Sci Bull 58:2992-2999

Zhang J, Zheng HG, Aarti A, Pantuwan G, Nguyen T, Tripathy JN, Sarial AK, Robin S, Babu RC, Nguyen BD, Sarkarung S, Blum A, Nguyen HT (2001) Locating genomic regions associated with components of drought resistance in rice: comparative mapping within and across species. Theor Appl Genet 103:19-29

\section{Submit your manuscript to a SpringerOpen ${ }^{\mathcal{O}}$ journal and benefit from:}

- Convenient online submission

- Rigorous peer review

- Immediate publication on acceptance

- Open access: articles freely available online

- High visibility within the field

- Retaining the copyright to your article

Submit your next manuscript at springeropen.com 